\title{
ANALISIS BIAYA INDUSTRI KECIL PENGOLAHAN KAYU DAN PERABOT DI PANGKALAN KERINCI KABUPATEN PELALAWAN (STUDI KASUS UD. AUZAR BERSAUDARA DAN UD. DIRGANTARA)
}

\author{
Mazni, Emy Sadjati, dan Enny Insusanty \\ IImu Kehutanan, Fakultas Kehutanan, Universitas Lancang Kuning \\ JIn. Yos Sudarso Km. 8 Rumbai Pekanbaru Riau \\ Email:maznie_yuo@rocketmail.com,emy_mnhunilak@gmail.com dan \\ annovisa@yahoo.com
}

\begin{abstract}
Wood processing and furniture industries are industries that convert wood into processed wood in the form of items such as tables, chairs, cabinets and others. UD. Auzar Bersaudara and UD. Dirgantara is an industry engaged in wood processing and furniture. UD wood furniture manufacturing and processing capacity. UD Auzar Bersaudara 667 units / year, with selling price / unit about $R p 135,000-R p 1,100,000$. The results show that the total net profit of UD wood processing and furniture industries. Auzar Bersaudara Rp 178.359.699 / year. The value of BCR of wood processing and furniture industry UD. Auzar Bersaudara is 1.48, then the business is feasible. So it can expand its business further by enlarging the business in other ways. UD wood furniture manufacturing and processing capacity. Capacity UD Dirgantara about 659 units, with selling price / unit about Rp 200,000- Rp 450,000. The results show that the total net profit of UD wood processing and furniture industries. UD Dirgantara for 1 year amounting to Rp 159,531,733 / year. The value of BCR of wood processing and furniture industry UD. Dirgantara is 1.36, then the business is feasible to be implemented. So it can expand its business further by enlarging the business in other ways.
\end{abstract}

Keywords: Wood processing, small industry, production cost, feasibility analysis

\section{PENDAHULUAN}

\section{Latar Belakang}

UD. Auzar Bersaudara dan

UD. Dirgantara merupakan industri yang bergerak dalam usaha pengolahan kayu dan perabotan. UD. Auzar Bersaudara didirikan pada tahun 1995 yang memproduksi perabot saja seperti, lemari, meja, dan kursi. Bahan baku yang digunakan UD. Auzar Bersaudara adalah kayu yang berasal dari alam, seperti meranti dan punak. UD. Dirgan-tara 
didirikan pada tahun 2002 yang memproduksi perabot saja seperti, lemari, meja, dan kursi. Bahan baku yang digunakan UD. Dirgantara adalah kayu yang berasal dari alam. UD. Auzar Bersaudara dan UD. Dirgantara tentunya sangat memerlukan adanya perhitungan terhadap biaya produksi. Oleh karena itu diperlukan kecermatan dalam menghi-tung biaya-biaya yang dikeluarkan. Perhitungan biaya produksi sangat berpengaruh terhadap penentuan harga pokok produksi dan harga jual. Berdasarkan alasan tersebut sehingga perlu dilakukan penelitian tentang "Analisis Biaya Industri Kecil Pengolahan Kayu dan Perabot di Pangkalan Kerinci Kabupaten Pelalawan (Studi Kasus UD. Auzar Bersaudara dan UD. Dirgantara)."

Rumusan masalah dalam penelitian ini adalah berapa biaya produksi yang dianggarkan oleh UD. Auzar Bersaudara dan UD. Dirgantara dan apakah UD. Auzar Bersaudara dan UD. Dirgantara layak dikembangkan. Sedangkan tujuan penelitian adalah mengetahui biaya produksi yang dianggarkan oleh UD. Auzar Bersaudara dan UD. Dirgantara dan menganalisis kelayakan usahanya.

Hasil penelitian ini diharapkan dapat memberikan acuan dalam pengambilan keputusan dalam memaksimalkan keuntungan usaha sehingga diharapkan pengelolaan kegiatan industri yang efektif dan efisien dapat tercapai sesuai dengan yang diinginkan.

\section{METODE PENELITIAN}

\section{Tempat dan Waktu}

Penelitian ini dilakukan pada industri UD. Auzar Bersaudara dan UD. Dirgantara yang beralamat di Pangkalan Kerinci, Kabupaten Pelalawan Propinsi Riau. Penelitian ini dilaksanakan selama 4 bulan, yaitu pada bulan Oktober 2016 sampai Bulan Januari 2017.

Objek Penelitian, Bahan dan Alat

Objek yang menjadi fokus penelitian ini adalah industri kecil UD. Auzar Bersaudara dan UD. 
Dirgantara. alat yang digunakan dalam penelitian ini adalah alat tulis, kamera, kalkulator, perekam suara. Sedangkan bahan digunakan adalah daftar pertanyaan, tally sheet.

\section{Metode Penelitian}

Metode yang digunakan dalam penelitian ini adalah metode survey, pelaksanaan penelitiannya dimulai dari observasi dan wawancara.

\section{Observasi}

Observasi merupakan suatu cara pengumpulan data dan melakukan pengamatan langsung terhadap suatu objek kemudian melakukan pencatatan secara sistematis tentang hal-hal tertentu yang sedang diamati. Dalam penelitian ini, peneliti akan melakukan observasi mengenai permasalahan yang akan diteliti yang berkaitan rumusan dan tujuan penelitian.

\section{Wawancara}

Dalam penelitian ini, penulis melakukan wawancara kepada pemilik dan karyawan UD. Auzar
Bersaudara dan UD. Dirgantara dengan mengajukan pertanyaanpertanyaan mengenai harga pokok produksi. Data yang dapat dikumpulkan antara lain: biaya bahan baku, biaya tenaga kerja, biaya overhead pabrik, penetapan harga jual menurut perusahaan dan sebagainya.

\section{Metode Pengumpulan Data}

Pengumpulan data yang diperoleh dalam penelitian ini adalah data primer dan data sekunder.

\section{Data Primer}

Data primer yang dikumpulkan adalah komponen biaya produksi, aspek pasar finansial dan pemasaran produk, seperti: biaya penyediaan bahan baku, upah tenaga kerja, biaya peralatan, biaya listrik, biaya perawatan mesin-mesin, biaya penyusutan nilai-nilai mesin dan yang dipakai dalam pembuatan furniture serta harga produk, volume penjualan setiap produk yang dikumpulkan data nya selama 1 kali produksi. 


\section{Data Sekunder}

Data sekunder adalah data yang berbentuk tulisan atau dokumen yang diperlukan, bersumber dari instansi terkait berupa dokumentasi dan kepustakaan yang relevan dengan masalah penelitian. Data sekunder diperoleh dari arsiparsip industri kecil seperti: keadaan umum UD. Auzar Bersaudara dan UD. Dirgantara, sejarahnya, pembukuan, tujuan pemasaran dan sumber modalnya.

\section{Pengolahan Data}

Pengolahan data dilakukan dengan bantuan kalkulator dan komputer program microsoft excel.

\section{Analisis Data}

Analisis data dilakukan dengan analisis kuantitatif dan analisis data kualitatif dengan menggunakan metode full costing. Analisis kualitatif dilakukan untuk melihat gambaran umum dan khusus dari lokasi kajian, saluran pemasaran dan struktur pemasaran. Analisis kuantitatif untuk melihat kelayakan usaha, keragaman pasar dengan analisis margin pemasaran. Secara ringkas tahapan analisis dan model analisis yang digunakan untuk menjawab tujuan penelitian adalah:

\section{Penghitungan Biaya Penyusutan \\ Perhitungan biaya produksi} dilakukan terhadap masingmasing produk yang dihasilkan, yaitu meja, kursi dan lemari. Menurut Wiradinata (1981 diacu dalam Asyifa 2012), biaya penyusutan dapat dihitung antara lain dengan metode garis lurus, rumus umumnya adalah :

$$
\text { Penyusutan pertahun }=\frac{\mathrm{M}-\mathrm{R}}{\mathrm{N}}
$$

\section{Dimana :}

$$
\begin{aligned}
\mathrm{M}= & \text { harga beli asset (Rupiah) } \\
\mathrm{R}= & \text { nilai sisa atau harga } \\
& \text { rongsokan } 10 \% \text { dari harga } \\
& \text { baru (Rupiah) } \\
\mathrm{N}= & \text { masa pakai (Tahun) }
\end{aligned}
$$

\section{Penghitungan Biaya Produksi}

Untuk mengetahui besarnya biaya produksi, semua komponen biaya di kelompokkan menjadi biaya tetap dan biaya tidak tetap. Total penjumlahan keduanya 
merupakan total biaya produksi. Biaya tetap dan biaya tidak tetap pada industri ini adalah:

a. Biaya Tetap (fixed cost), terdiri dari : gaji pegawai, administrasi, peme-liharaan dan reparasi peralatan dan bangunan, penyusutan, listrik, bbm, dan biaya lain-lain

b. Biaya Tidak Tetap (variable cost), terdiri dari : Bahan baku, dan upah tenaga kerja. Menurut Duer et. al, (1976) dalam Asyisifa (2009), rumus yang digunakan untuk menghitung biaya produksi adalah sebagai berikut :

\section{$\mathrm{TC}=\mathrm{FC}+\mathrm{VC}$}

Dimana :

$\mathrm{TC}=$ Total Cost $/$ Biaya Total (Rupiah)

FC= Fixed Cost/Biaya Tetap (Rupiah)

$\mathrm{VC}=$ Variable Cost/Biaya Variabel (Rp)

\section{Pendapatan}

Untuk menghitung besarnya pendapatan suatu industri, rumus yang digunakan menurut Ibrahim (2003) dalam Emawati (2007) adalah :

$$
\mathbf{T R}=\mathbf{P} \times \mathbf{Q}
$$

Dimana :

$T R=$ Total pendapatan $(R p)$

$Q=$ Jumlah output yang dijual (unit)

$P=$ Harga jual per satuan unit (Rp)

\section{Keuntungan Bersih (Net Profit)}

Untuk mengetahui besarnya keuntungan digunakan rumus (Wiradinata, 1981 diacu dalam Asyisifa, 2009) adalah :

$$
\text { NP }=\text { TR }- \text { TC }
$$

Dimana :

$$
\begin{aligned}
\mathrm{TR}= & \text { Total pendapatan } / \text { total revenue } \\
& (\mathrm{Rp}) \\
\mathrm{NP}= & \text { Besarnya keuntungan Net Profit } \\
& (\mathrm{Rp}) \\
\mathrm{TC}= & \text { Jumlah biaya } / \text { Total Cost }(\mathrm{Rp})
\end{aligned}
$$

\section{Penghitungan Biaya Pemasaran}

Besar keseluruhan biaya yang dikeluarkan dalam kegiatan pemasaran dihitung dengan menjumlahkan besar komponenkomponen biaya pemasaran tersebut seperti biaya pengangkutan dan biaya bongkar muat.

\section{Rumus Benefit Cost Ratio (BCR)}

Perhitungan rasio BCR merupakan perbandingan antara penerimaan total dan biaya total, 
yang menunjukkan nilai tetap (Fixed Cost) dan biaya tidak penerimaan yang diperoleh dari tetap (Variabel Cost). Selanjutnya setiap rupiah yang dikeluarkan. dilakukan pentabulasian besarnya Jika BCR $>1$, proyek dapat biaya produksi dan pemasaran dikatakan layak dikerjakan, selama satu kali produksi, sebagai sebaliknya jika nilai $\mathrm{BCR}<1$, proyek tersebut tidak layak untuk dikerjakan. Secara umum, rumus perhitungan BCR adalah:

$$
\begin{aligned}
\operatorname{BCR}(\mathrm{Rp}) & =\frac{B}{C} \\
\mathrm{~B} & =\text { Benefit }(\mathrm{Rp}) \\
\mathrm{C} & =\text { Cost }(\mathrm{Rp})
\end{aligned}
$$

Kriteria:

Jika $B / C>1=$ memberikan manfaat (untung)

Jika $\mathrm{B} / \mathrm{C}<1=$ tidak memberikan manfaat (rugi)

\section{HASIL DAN PEMBAHASAN}

Analisis ini dilakukan dengan menghitung semua komponen biaya produksi yang dapat dikategorikan sebagai biaya berikut:

\section{Biaya Variabel (Variabel Cost)}

a. Bahan Baku

$$
\text { Menurut Wijaya (2011) }
$$

Bahan baku merupakan bahan yang membentuk bagian menyeluruh produk jadi, bahan baku yang diolah dalam perusahaan manufaktur dapat diperoleh dari pembelian lokal, impor atau dari pengolahan sendiri. Adapun bahan baku yang digunakan dalam usaha pengolahan kayu dan perabot UD. Auzar Bersaudara dan UD. Dirgantara dapat dilihat pada Tabel 1 dibawah ini:

Tabel 1. Bahan Baku Yang Digunakan Dalam Usaha Pengolahan Kayu Dan Perabot UD. Auzar Bersaudara dan UD. Dirgantara

\begin{tabular}{|c|l|c|c|c|c|}
\hline \multirow{2}{*}{ No } & \multirow{2}{*}{ Bahan Baku } & \multicolumn{2}{|c|}{ UD. Auzar Bersaudara } & \multicolumn{2}{c|}{ UD. Dirgantara } \\
\cline { 3 - 6 } & & Ukuran $\mathbf{( m}^{\mathbf{3}} \mathbf{)}$ & Harga (Rp) & Ukuran $\mathbf{( m}^{\mathbf{3}} \mathbf{)}$ & Harga (Rp) \\
\hline 1 & Meranti & $4 \times 25 \times 400$ & 1.700 .000 & $4 \times 25 \times 400$ & 1.800 .000 \\
\hline 2 & Meranti Batu & - & - & $4 \times 25 \times 400$ & 2.000 .000 \\
\hline 3 & Kulim & $6 \times 13 \times 400$ & 3.500 .000 & $4 \times 25 \times 400$ & 3.500 .000 \\
\hline 4 & Kuras & - & - & $6 \times 13 \times 400$ & 1.800 .000 \\
\hline 5 & Punak & $6 \times 13 \times 400$ & 2.100 .000 & - & - \\
\hline 6 & Temonsu & $4 \times 25 \times 400$ & 7.000 .000 & - & - \\
\hline 7 & Rengas & $4 \times 25 \times 400$ & 1.900 .000 & - & - \\
\hline $\mathbf{8}$ & \multicolumn{2}{l}{ Total } & $\mathbf{1 6 . 2 0 0 . 0 0 0}$ & & $\mathbf{9 . 1 0 0 . 0 0 0}$ \\
\hline
\end{tabular}




\begin{tabular}{|l|c|c|c|c|c|}
\hline \multirow{2}{*}{ No } & \multirow{2}{*}{ Bahan Baku } & \multicolumn{2}{|c|}{ UD. Auzar Bersaudara } & \multicolumn{2}{c|}{ UD. Dirgantara } \\
\cline { 3 - 6 } & & Ukuran $\left(\mathrm{m}^{3}\right)$ & Harga (Rp) & Ukuran $\left(\mathrm{m}^{3}\right)$ & Harga (Rp) \\
\hline
\end{tabular}

Sumber: Data Primer 2016

Bahan baku yang digunakan untuk keperluan industri kecil Pengolahan kayu dan perabot UD. Auzar Bersaudara adalah berupa kayu meranti, punak, kulim, temonsu, dan rengas yang kualitasnya, tekstur yang bagus, awet, kuat dan tahan terhadap rayap. Pemakaian kayu $5 \mathrm{M}^{3}$ perbulan, jenis kayu yg sering dipakai adalah $2 \mathrm{M}^{3}$ kulim, $2 \mathrm{M}^{3}$ meranti dan $1 \mathrm{M}^{3}$ punak. Pemenuhan bahan baku untuk pembuatan perabotan ini didatangkan dari Desa Bukit Kesuma dan Teluk Meranti Kabupaten Pelalawan.

Bahan baku yang digunakan untuk keperluan industri UD. Dirgantara ini adalah berupa kayu meranti, meranti batu, kulim, dan kuras yang kualitasnya, tekstur yang bagus, awet, kuat dan tahan terhadap rayap. Pemakaian bahan baku sealama 1 bulan adalah 2 $\mathrm{M}^{3}$ Meranti, $1 \mathrm{M}^{3}$ Kulim dan $1 \mathrm{M}^{3}$ Kuras. Pemenuhan bahan baku untuk pembuatan perabotan ini didatangkan sama dengan UD Auzar Bersaudara.

\section{b. Biaya Tenaga Kerja}

Biaya Tenaga Kerja (BTK) merupakan gaji/upah karyawan bagian poduksi. Biaya Ini dibedakan menjadi biaya tenaga kerja langsung dan biaya tenaga kerja tidak langsung. Biaya tenaga kerja pada UD. Auzar Bersaudara dan UD. Dirgantara sebagai berikut:

Tabel 2. Biaya tenaga kerja pada UD.Auzar Bersaudara dan UD. Dirgantara

\begin{tabular}{|c|c|c|c|c|c|c|}
\hline $\begin{array}{l}\mathbf{N} \\
\mathbf{O}\end{array}$ & $\begin{array}{c}\text { Nama } \\
\text { Industri Kecil }\end{array}$ & Nama & $\begin{array}{c}\text { Upah } \\
\text { (Rp/hari) }\end{array}$ & $\begin{array}{c}\text { Gaji } \\
\text { (Rp/Bulan) }\end{array}$ & $\begin{array}{c}\text { Gaji } \\
\text { (Rp/tahun) }\end{array}$ & Ket \\
\hline \multirow{3}{*}{1} & \multirow{3}{*}{$\begin{array}{l}\text { UD. Auzar } \\
\text { Bersaudara }\end{array}$} & Mudas & 100.000 & 2.200 .000 & 26.400 .000 & \multirow{4}{*}{$\begin{array}{l}\text { Upah } \\
\text { harian }\end{array}$} \\
\hline & & Abdul Gaus & 100.000 & 2.200 .000 & 26.400 .000 & \\
\hline & & $\begin{array}{l}\text { Saidina } \\
\text { Umar }\end{array}$ & 85.000 & 1.870 .000 & 22.400 .000 & \\
\hline \multicolumn{4}{|c|}{ Total } & 6.270 .000 & 75.240 .000 & \\
\hline \multirow{2}{*}{2} & \multirow{2}{*}{$\begin{array}{l}\text { UD. } \\
\text { Dirgantara }\end{array}$} & Imam & - & 2.675 .000 & 33.180 .000 & \multirow{3}{*}{$\begin{array}{l}\text { Upah } \\
\text { borong } \\
\text { an }\end{array}$} \\
\hline & & Yokki & - & 2.675 .000 & 33.180 .000 & \\
\hline & & Total & & 5.530 .000 & 66.360 .000 & \\
\hline
\end{tabular}




\begin{tabular}{|c|c|c|c|c|c|c|}
\hline $\mathbf{N}$ & Nama & Nama & $\begin{array}{c}\text { Upah } \\
\text { (Rp/hari) }\end{array}$ & $\begin{array}{c}\text { Gaji } \\
\text { (Rp/Bulan) }\end{array}$ & $\begin{array}{c}\text { Gaji } \\
\text { (Rp/tahun) }\end{array}$ & Ket \\
\hline
\end{tabular}

Sumber : Data Primer 2016

Pembayaran tenaga kerja karyawan yang sudah lama karyawan UD. Auzar Bersaudara bekerja. Karyawan yang bekerja di dilakukan setiap bulannya. Upah UD. Dirgantara adalah tenaga karyawan yang dibayarkan oleh kerja borongan yang berjumlah 2 UD. Auzar Bersaudara setiap orang. Pembayaran tenaga kerja bulannya sebesar $\operatorname{Rp~6.270.000,~}$ borongan pada UD. Dirgantara untuk 3 orang karyawan. dibayar sesuai dengan jenis dan Pembayaran upah karyawan di jumlah perabot yang dikerjakan.

\section{UD. Auzar Bersaudara}

berdasarkan lamanya karyawan bekerja. Agar pembayaran upah karyawan baru dengan karyawan senior sama tergantung dari skill karyawan itu sendiri, apabila karyawan tersebut cepat ahli dalam semua bidang yang dikerjakan maka upah yang

\section{c. Bahan Penunjang}

Selain bahan baku, industri pengolahan kayu ini membutuhkan bahan penunjang. Bahan penunjang yang digunakan UD. Auzar Bersaudara dan UD. Dirgantara dapat dilihat pada Tabel 3, berikut:

diterima akan disamakan dengan

\section{Tabel 3. Bahan Penunjang yang Digunakan D.Auzar Bersaudara dan} UD. Dirgantara

\begin{tabular}{|c|l|l|r|l|r|}
\hline \multirow{2}{*}{ No } & \multirow{2}{*}{ Nama } & \multicolumn{2}{|c|}{ UD. Auzar Bersaudara } & \multicolumn{2}{c|}{ UD. Dirgantara } \\
\cline { 3 - 6 } & & \multicolumn{1}{|c|}{ Pemakaian } & $\begin{array}{c}\text { Harga } \\
\text { (Rp/tahun) }\end{array}$ & \multicolumn{1}{|c|}{ Pemakaian } & $\begin{array}{c}\text { Harga } \\
\text { (Rp/tahun) }\end{array}$ \\
\hline 1 & Gomok & 1 tahun per kaleng & 25.000 & $\begin{array}{l}\text { 1 tahun per } \\
\text { kaleng }\end{array}$ & 25.000 \\
\hline 2 & Paku & 1 hari 2 Kg & 3.960 .000 & 1 hari 2 Kg & 7.920 .000 \\
\hline 3 & Cat & 9 kaleng cat/bulan & 4.644 .000 & 3 kaleng/ bulan & 1.548 .000 \\
\hline 4 & Lem & 5 hari 1 bungkus & 880.000 & $\begin{array}{l}\text { 5 hari 1 } \\
\text { bungkus }\end{array}$ & 880.000 \\
\hline 5 & Tiner & 3 kaleng/bulan & 720.000 & $\begin{array}{l}\text { 1 kaleng 5 kilo } \\
\text { cat }\end{array}$ & 240.000 \\
\hline 6 & Amplas & 3 lembar 1 hari & 1.760 .000 & 3 lembar 1 hari & 1.760 .000 \\
\hline
\end{tabular}




\begin{tabular}{|c|l|l|c|c|c|}
\hline \multirow{2}{*}{ No } & \multirow{2}{*}{ Nama } & \multicolumn{2}{|c|}{ UD. Auzar Bersaudara } & \multicolumn{2}{c|}{ UD. Dirgantara } \\
\cline { 3 - 6 } & & \multicolumn{1}{|c|}{ Pemakaian } & $\begin{array}{c}\text { Harga } \\
\text { (Rp/tahun) }\end{array}$ & Pemakaian & $\begin{array}{c}\text { Harga } \\
\text { (Rp/tahun) }\end{array}$ \\
\hline 7 & Kaca & 1 Lembar 1 hari & 29.920 .000 & 1 Lembar 1 hari & 30.800 .000 \\
\hline 8 & Triplek & $\begin{array}{l}\text { 11 lembar } \\
\text { triplek/bulan }\end{array}$ & 9.768 .000 & 3 lembar/bulan & 2.160 .000 \\
\hline \multicolumn{2}{|c|}{\begin{tabular}{c} 
Total \\
\cline { 3 - 5 }
\end{tabular}} \\
\hline
\end{tabular}

Sumber: Data Primer 2016

Bahan penunjang yang

menjadi wajar.

Untuk

digunakan UD. Auzar Bersaudara menyusutkan peralatan atau persama dengan yang digunakan lengkapan yang digunakan tetap oleh UD. Dirgantara. Untuk harus diperhitungkan terlebih melengkapi dan menyempurnakan dahulu harga perolehan, umur bahan baku yang akan dibentuk, bahan penunjang tersebut digunakan sesuai dengan manfaat dan keperluannya.

\section{Biaya Tetap (Fixed Cost)}

\section{a. Biaya Penyusutan Alat}

Perhitungan

biaya

penyusutan sangat penting dilakukan dalam usaha karena pengakuan terhadap beban penyusutan setiap tahun dapat digunakan sebagai alokasi perusahaan untuk membeli peralatan atau perlengkapan baru jika masa manfaat perlengkapan atau peralatan lama telah habis. Selain itu beban penyusutan juga memegang peranan penting dalam ketepatan perhitungan harga pokok penjualan se-hingga perhitungan laba rugi perusahaan pakai, manfaat dan nilai residunya.

Hasil perhitungan total nilai investasi UD. Auzar Bersaudara adalah sebesar $\operatorname{Rp~} 67,100,000$ dengan nilai penyusutan total selama satu tahun adalah $\mathrm{Rp}$ 12,078,000. Total nilai investasi UD. Dirgantara adalah sebesar Rp $57,850,000$ dengan nilai penyusutan total selama satu tahun adalah $\operatorname{Rp} 12,268,733$. Nilai tersebut merupakan biaya yang dibebankan terhadap biaya produksi akibat pengeluaran aktiva tetap dalam proses produksi.

Peralatan mempunyai nilai yang semakin berkurang dari suatu periode ke periode berikutnya. Penyusutan per-alatan biasanya batas waktunya selama 
5 tahun. Selain itu beban ataupun badan yang sifatnya penyusutan juga memegang memaksa namun tetap peranan penting dalam ke-tepatan berdasarkan pada undang-undang perhitungan harga pokok dan tidak terdapat imbalan secara penjualan sehingga perhitungan langsung serta digunakan untuk laba rugi perusahaan menjadi wajar. kebutuhan Negara juga kemakmuran rakyatnya.

UD. Auzar Bersaudara

b. Biaya

Penyusutan

\section{Bangunan}

Dari hasi kepada pemilik UD. Auzar Bersaudara dan UD. Dirgantara nilai bangunan selama satu tahun sebesar Rp 7.000.000. Menurut Kasmir dan Jakfar (2012 dalam Putri 2016) investasi dapat diartikan sebagai penanaman modal dalam suatu kegiatan yang memiliki jangka waktu relatif panjang dalam berbagai bidang usaha.

Selain biaya investasi dan penyusutan, UD. Auzar Bersaudara dan UD. Dirgantara juga mengeluarkan biaya berbentuk pajak. Menurut UU No. 28 Tahun 2007 Pasal 1 Tentang Ketentuan Umum Dan Perpajakan, pajak adalah suatu konstribusi wajib kepada Negara yang terhutang oleh setiap orang iri berdasarkan Surat ljin dari Kantor Pelayanan Perizinan Terpadu (SITU) Kecil Nomor.137/KPPT/HO/2011/122, yang disahkan oleh Kepala Kantor Pelayanan Perijinan Terpadu. Pengurusan biaya izin usaha pada tahun 2016 sebesar Rp. 3.500.000, dibebankan pajak tiap tahunnya sebesar $\operatorname{Rp} 700,000$. UD. Dirgantara berdiri berdasarkan Surat Ijin Usaha Perdagangan (SIUP) Kecil Nomor 137/KPPT/SIUP-K/2012/332, yang di tanda tangani oleh Kepala Pelayanan Perijinan Terpadu Kabupaten Pelalawan. Pengurusan biaya izin usaha pada tahun 2002 sebesar Rp. 2.000.000, dibebankan pajak tiap ta-hunnya sebesar $\operatorname{Rp} 700,000$. Pembayaran pajak PBB, izin usaha, dan mobil dibayar tiap tahunnya. 


\section{c. Biaya Pemasaran}

Biaya pemasaran adalah semua biaya yang sejak saat produk selesai diproduksi dan disimpan dalam gudang sampai dengan produk tersebut berubah kembali dalam bentuk uang tunai (Mulyadi, 2010). Dari pengertian diatas dapat disimpulkan bahwa biaya pemasaran adalah biaya yang dikeluarkan untuk menjual produk atau barang dagangan sampai ke tangan konsumen. Biaya pemasaran pada industri pengolahan kayu dan perabot UD. Auzar Bersaudara dan UD. Dirgantara terdapat pada Tabel 4, berikut:

Tabel 4. Biaya Pemasaran Pada Industri Pengolahan Kayu Dan Perabot UD. Auzar Bersaudara dan UD. Dirgantara

\begin{tabular}{|c|c|c|c|}
\hline \multirow{2}{*}{$\begin{array}{c}\text { N } \\
\mathbf{0}\end{array}$} & \multicolumn{1}{|c|}{ Uraian Biaya } & \multicolumn{2}{|c|}{ Biaya (Rp)/tahun } \\
\cline { 3 - 4 } & $\begin{array}{c}\text { UD. Auzar } \\
\text { Bersaudara }\end{array}$ & $\begin{array}{c}\text { UD. } \\
\text { Dirgantara }\end{array}$ \\
\hline 1 & $\begin{array}{l}\text { Biaya pengiriman barang dari gudang penjualan } \\
\text { ke tempat konsumen }\end{array}$ & 3.200 .000 & 4.200 .000 \\
\hline 2 & Biaya bongkar muat barang ke tempat penjualan & 2.200 .000 & 3.000 .000 \\
\hline & Total & $\mathbf{5 . 4 0 0 . 0 0 0}$ & $\mathbf{7 . 2 0 0 . 0 0 0}$ \\
\hline
\end{tabular}

Sumber : Data Primer 2016

Dari tabel diatas, biaya pemasaran pada industri pemasaran pada industri pengolahan kayu dan perabot UD. pengolahan kayu dan perabot UD. Dirgantara sebesar Rp Auzar Bersaudara sebesar Rp 7.200.000/tahun. Biaya 5.400.000/tahun.Produk pengolahan kayu dan perabot UD. pengiriman barang dan bongkar Auzar Bersaudara ini dipasarkan muat diatas adalah selama 1 kali produksi. Produk pengolahan disekitar daerah Pangkalan kayu dan perabot UD. Dirgantara Kerinci. Lokasi UD. Auzar ini dipasarkan disekitar daerah Bersaudara ini dekat dengan lokasi sekolah sehingga produk yang dihasilkan seperti kursi, meja dan lemari lebih mudah dan dekat dalam pengangkutannya. Biaya Pangkalan Kerinci. Biaya pengiriman barang dari gudang penjualan hingga ke tempat sudah termasuk biaya supir, diluar dari biaya bahan bakar minyak. Biaya 
supir dibayarkan berdasarkan jauh dekatnya lokasi pengiriman barang.

\section{d. Biaya Lain-Lain}

Biaya lain-lain merupakan biaya tambahan dalam industri seperti biæy.a listrik, biaya telepon, BBM, Nilai Bangunan /Workshop atau upah tenaga administratif. Dari perhitungan, UD. Auzar bersaudara mengeluarkan pembayaran untuk biaya lainlainnya untuk 1 kali produksi sebesar Rp 15.677.000. UD. Dirgantara menge-luarkan pembayaran untuk biaya lainlainnya untuk 1 kali produksi sebesar Rp 45.333.000.

Pembayaran biaya lain-lainnya antara UD. Auzar Bersaudara dengan UD. Dirgantara berbeda, terdapat selisih $\mathrm{Rp}$ 6.344.000. Biaya yang dikeluarkan oleh UD. Auzar Bersaudara lebih besar dibanding UD Dirgantara.

\section{Total Biaya Produksi}

Pengendalian biaya produksi diper-lukan bagi perusahaan agar perusahaan dapat mencapai laba yang maksimal dengan biaya yang rendah. Kebutuhan biaya operasional yang dikeluarkan UD. Auzar Bersaudara dan UD. Dirgantara secara keseluruhannya dalam menjalankan usaha dapat dilihat pada gambar berikut:

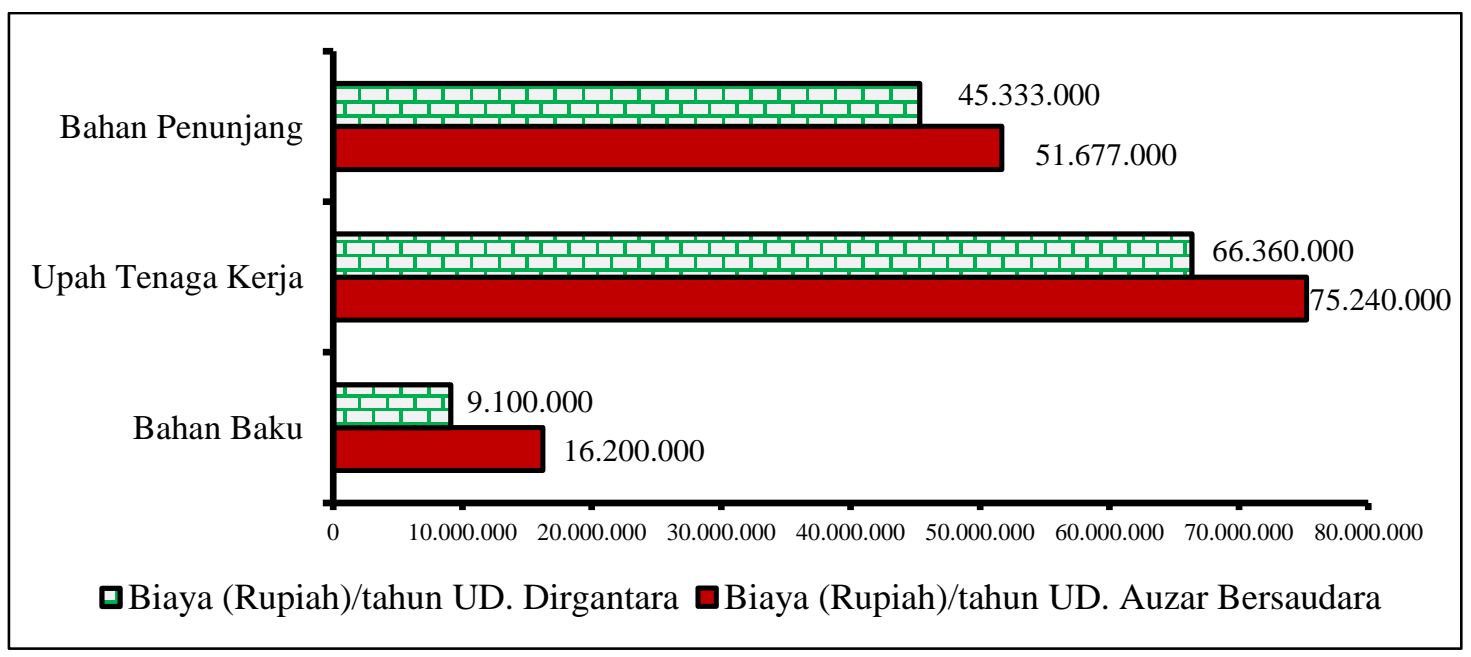

\section{Gambar 1. Perbandingan Komponen Biaya Variabel}




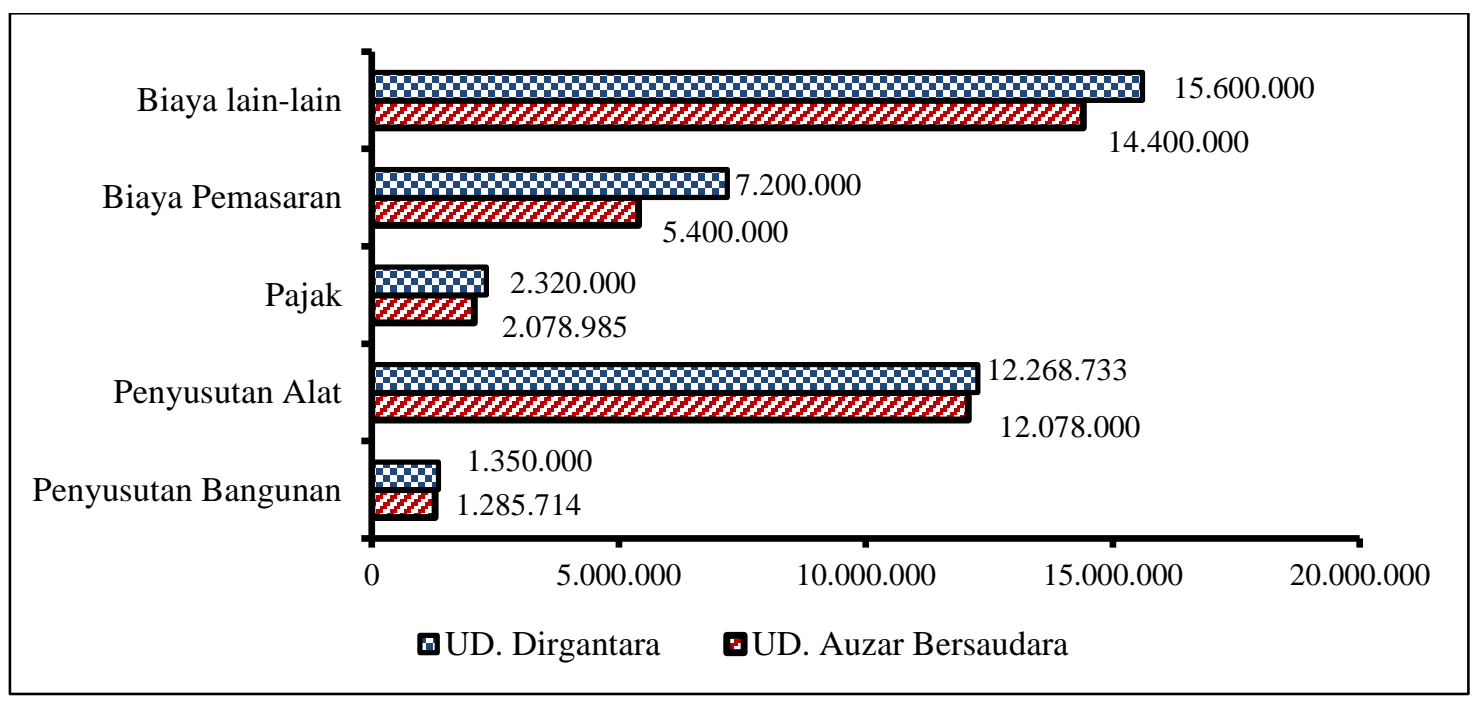

\section{Gambar 2. Perbandingan Biaya Tetap}

Besarnya biaya produksi Auzar Bersaudara dengan UD. yang dikeluarkan untuk Dirgantara sebesar $R p$ pembuatan keenam jenis 18.827.966. Biaya produksi UD. pengolahan kayu dan perabotan Auzar Bersaudara lebih besar ini yaitu meja, pintu, kursi, lemari, daripada UD. Dirgantara. Selisih kusen dan jendela dalam 1 tahun biaya tersebut karena pada awal buka UD. Auzar penggunaan bahan baku, tenaga Bersaudara pada tahun 2016 kerja, bbm, listrik serta peralatan adalah Rp 178.359.699. Besarnya yang berbeda. Produk yang biaya produksi yang dikeluarkan dihasilkan oleh UD. Auzar oleh UD. Dirgantara untuk Bersaudara lebih banyak pembuatan kelima jenis daripada UD. Dirgantara. pengolahan kayu dan perabotan Sehingga membuat biaya ini yaitu meja, kursi, pintu, kusen produksi UD. Auzar Bersaudara dan jendela dalam 1 tahun pada lebih tinggi. Besarnya biaya tahun 2016 adalah $\mathrm{Rp}$ 159.531.733.

Dari gambar diatas, terdapat selisih antara biaya produksi UD. produksi merupakan besarnya pembebanan yang diperhitungkan atas pemakaian faktor-faktor produksi yang berupa bahan, 
tenaga kerja, peralatan dan mesin untuk menghasilkan suatu produk. Biaya produksi bergantung pada teknik produksi yang digunakan untuk memproduksi barang tersebut (Hermanto, 2009).

\section{Produk Yang Dihasilkan}

Menurut Harsono (1994:4) diacu dalam (Iryadini, 2010) produksi adalah setiap usaha manusia / kegiatan yang membawa benda kedalam suatu keadaan sehingga dapat dipergunakan untuk kebutuhan manusia dengan lebih baik. Awal didirikannya UD. Auzar Bersaudara hanya memproduksi 3 jenis barang seperti meja, kursi dan lemari. Karena lokasi UD. Auzar Bersaudara dekat dengan areal sekolah maka industri tersebut hanya memproduksi untuk memenuhi kebutuhan sekolah. Harga per unit perabot ini berkisar antara Rp 135.000-, sampai dengan $\mathrm{Rp}$ 900.000Seiring berkembangnya kebutuhan masyarakat pemilik UD. Auzar Bersaudara mulai mengembangkan usahanya dengan menambah produk seperti jendela, kusen, pintu dengan harga yang bervariasi sesuai dengan ukuran.

Jenis Produk yang dihasilkan pada UD. Auzar Bersaudara pada tahun 2016 ada 6 macam, yaitu jendela, kusen, pintu, kursi, meja dan lemari dengan bentuk dengan harganya. Harga per unit perabot ini berkisar antara $\mathrm{Rp}$ 135.000-, sampai dengan Rp 1.100.000-,. Berdasarkan hasil penelitian diketahui bahwa realisasi produksi perabotan 1 tahun terakhir sebesar 667 unit dimana kursi diproduksi sebanyak 98 unit, lemari sebanyak 41 unit, meja sebanyak 56 unit, kusen 164 unit, pintu 143 unit dan jendela 162 unit. Jenis perabot yang paling banyak diproduksi dalam 1 tahun adalah kusen kemudian jendela, dan yang terendah adalah lemari. Proses pembuatan perabotan ini memerlukan waktu yang berbeda, untuk kursi memerlukan waktu atara 1 hari, meja dapat direalisasikan dalam waktu 1 hari sedangkan lemari dapat diselesaikan dalam waktu 23 hari, kusen 1 hari, pintu dan jendela 1-2 hari. 
Produk yang didihasilkan oleh UD. Dirgantara ini pada awal berdiri usahanya adalah lemari, meja dan kursi. Pada tahun 2016 pemilik UD. Dirgantara menambah produknya menjadi 5 macam, yaitu jendela, kusen, pintu, kursi, dan meja dengan bentuk dengan harganya. Penambahan produk tersebut dikare-nakan banyak kebutuhan dan permintaan dari masyarakat. Harga per unit perabot ini berkisar antara $\mathrm{Rp}$ 200.000-, sampai dengan Rp 450.000-,. Berdasarkan hasil penelitian diketahui bahwa realisasi produksi perabotan 1 tahun terakhir sebesar 659 unit dimana kursi diproduksi sebanyak 95 unit, jendela sebanyak 196 unit, kusen sebanyak 186 unit, pintu sebanyak 130 unit dan meja sebanyak 52 unit. Jenis perabotan yang paling banyak diproduksi dalam 1 tahun adalah jendela, kemudian kusen dan yang terendah adalah meja. Proses pembuatan perabot ini memerlukan waktu yang berbeda, untuk kursi memerlukan waktu atara 4-5 hari, meja dapat direalisasikan dalam waktu 1 hari sedangkan kusen dan jendela dapat diselesaikan dalam waktu 23 hari.

\section{Pendapatan}

Perhitungan pendapatan usaha pengolahan kayu dan perabot UD. Auzar Bersaudara dan UD. Dirgantara diperoleh dengan cara mengurangi nilai harga jual secara keseluruhan produk. Untuk melihat rincian pendapatan UD. Auzar Bersaudara dan UD. Dirgantara dapat dilihat pada Tabel 5 berikut:

Tabel 5. Rincian Penjualan UD. Auzar Bersaudara dan UD. Dirgantara Tahun 2016

\begin{tabular}{|c|l|c|c|}
\hline \multirow{2}{*}{ No } & \multirow{2}{*}{ Bulan } & \multicolumn{2}{c|}{ Pendapatan (Rp) } \\
\cline { 3 - 4 } & & UU. Auzar Bersaudara & UD. Dirgantara \\
\hline 1 & Januari & 18.000 .000 & 14.000 .000 \\
\hline 2 & Februari & 25.000 .000 & 17.000 .000 \\
\hline 3 & Maret & 15.000 .000 & 20.000 .000 \\
\hline 4 & April & 20.000 .000 & 18.000 .000 \\
\hline 5 & Mei & 25.000 .000 & 15.000 .000 \\
\hline
\end{tabular}




\begin{tabular}{|c|c|c|c|}
\hline \multirow{2}{*}{ No } & \multirow{2}{*}{ Bulan } & \multicolumn{2}{|c|}{ Pendapatan (Rp) } \\
\hline & & UU. Auzar Bersaudara & UD. Dirgantara \\
\hline 6 & Juni & 19.000 .000 & 20.000 .000 \\
\hline 7 & Juli & 23.000 .000 & 16.000 .000 \\
\hline 8 & Agustus & 21.000 .000 & 20.500 .000 \\
\hline 9 & September & 22.000 .000 & 22.000 .000 \\
\hline 10 & Oktober & 30.000 .000 & 18.000 .000 \\
\hline 11 & November & 22.000 .000 & 20.000 .000 \\
\hline 12 & Desember & 25.017 .000 & 17.668 .500 \\
\hline & Total & $265,017,000$ & 218.168.500 \\
\hline
\end{tabular}

Sumber: Data Primer 2016

Pendapatan yang

diperoleh selama 1 tahun sebesar

Rp 265.017.000-, hal ini menunjukkan bahwa hasil industri pengolahan kayu yang dihasilkan oleh UD. Audzar Bersaudara cukup diminati masyarakat kota Pangkalan Kerinci dan sekitarnya, karena harga jualnya masih terjangkau oleh konsumen dibandingkan dengan harga jual mebel kayu jati dan dibandingkan dengan hasil produk industri yang lain. Pendapatan yang diperoleh selama 1 tahun sebesar $\mathrm{Rp}$ 218.168.500-, hal ini menunjukkan bahwa hasil industri pengolahan kayu yang dihasilkan oleh UD. Dirgantara cukup diminati masyarakat kota Pangkalan Kerinci dan sekitarnya.

Terdapat selisih antara Pendapatan UD.Auzar
Bersaudara dengan UD.Dirgantara sebesar Rp 44.848.500. Biaya produksi UD. Auzar Bersaudara lebih besar daripada UD. Dirgantara.Selisih biaya tersebut karena jumlah produk yang dihasilkan oleh UD. Auzar Bersaudara lebih banyak daripada UD. Dirgantara. Sehingga membuat pendapatan UD. Auzar Bersaudara lebih tinggi.

\section{Keuntungan}

Laba bersih adalah kelebihan seluruh pendapatan atas seluruh biaya untuk suatu periode tertentu setelah dikurangi pajak penghasilan yang disajikan dalam bentuk laporan laba rugi. Semakin cepat tingkat pertumbuhan perusahaan, semakin besar kebutuhan akan 
dana untuk membiayai perluasan.

Biaya-biaya produksi yang terjadi setiap periode selalu mempengaruhi laba yang diperoleh perusahaan. Oleh karena itu, biaya-biaya yang terjadi diperusahaan perlu dianalisis untuk mengetahui seberapa besar pengaruhnya terhadap laba yang diperoleh perusahaan. produksi tersebut digunakan untuk kepentingan perusahaan guna memper-lancar kegiatan operasional perusahaan. Untuk mengetahui besarnya keuntungan yang dihasilkan UD. Auzar Bersaudara dan UD. Dirgantara dapat dilihat pada Tabel 6 berikut:

Tabel 6. Keuntungan UD. Auzar Bersaudara dan UD. Dirgantara

\begin{tabular}{|c|l|c|c|}
\hline \multirow{2}{*}{ No } & \multirow{2}{*}{ Rincian } & \multicolumn{2}{|c|}{ Jumlah (Rp) } \\
\cline { 3 - 4 } & & $\begin{array}{c}\text { UD. Auzar } \\
\text { Bersaudara }\end{array}$ & UD. Dirgantara \\
\hline 1 & Pendapatan total & 265.017 .000 & 218.168 .500 \\
\hline 2 & Pengeluaran total & 178.359 .699 & 159.531 .733 \\
\hline 3 & Keuntungan total & 86.657 .301 & 58.636 .767 \\
\hline
\end{tabular}

Sumber: Data Primer 2016

Berdasarkan asumsi dan parameter teknis yang telah ditentukan sebelumnya, kapasitas produksi perabotan dan pengolahan kayu UD. Auzar Bersaudara mencapai 667 unit, per tahun dengan harga jual per unit sekitar $R p$ 135.000- $R p$ 1.100.000. Jumlah keuntungan bersih UD. Auzar Bersaudara selama 1 tahun sebesar $R p$ 86.657.301.

Sedangkan kemampuan produksi perabotan dan pengolahan kayu UD. Dirgantara mencapai 659 unit per tahun, dengan harga jual/unit sekitar Rp 200.000- Rp 450.000. Jumlah keuntungan bersih UD. Dirgantara selama setahun sebesar $R p$ 58.636.767. Dari hasil perhitungan keuntungan tersebut terdapat selisih keuntungan yang diperoleh UD. Auzar Bersaudara dan UD. Dirgantara sebesar Rp 28.020.534. Selisih biaya tersebut karena jumlah produk yang dihasilkan dan yang laku terjual oleh UD. Auzar Bersaudara lebih banyak daripada UD. Dirgantara. Sehingga membuat keuntungan 
UD. Auzar Bersaudara lebih tinggi.

\section{Analisis Kelayakan}

\section{BCR (benefit cost ratio)}

Untuk mengetahui besarnya nilai BCR UD. Auzar Bersaudara dan UD. Dirgantara dapat dilihat pada uraian berikut:

d. BCR (Benefit Cost Rasio) UD. Auzar Bersaudara

$$
\mathrm{BCR}=\frac{B}{C}+\frac{265.017 .000}{178.359 .699}=\mathbf{1 , 4 8}
$$

a. BCR (Benefit Cost Rasio) UD. Dirgantara

$$
\mathrm{BCR}=\frac{B}{C}+\frac{218.168 .500}{159.531 .733}=\mathbf{1}, \mathbf{3 6}
$$

Kriteria BCR:

Jika $B / C>1=$ memberikan manfaat (untung)

Jika $\mathrm{B} / \mathrm{C}<1=$ tidak memberikan manfaat (rugi)

Hasil penelitian menunjukkan bahwa BCR industri pengolahan kayu dan perabotan UD. Auzar Bersaudara adalah 1,48. Dan Nilai BCR industri pengolahan kayu dan perabotan UD. Dirgantara adalah 1,36. Karena nilai BCR UD. Auzar Bersaudara dan UD.Dirgantara > 1, maka usaha tersebut memberikan manfaat artinya usaha tersebut layak dilaksanakan. Sehingga dapat mengembangkan usahanya lebih lanjut dengan cara memperbesar usaha dengan cara lainnya.

\section{KESIMPULAN DAN SARAN}

\section{Kesimpulan}

Dari hasil pembahasan diatas dapat disimpulkan:

1. Biaya produksi pengolahan kayu dan perabotan UD. Auzar Bersaudara adalah Rp. 178.359.699 pertahun, dengan volume produksi rata-rata sebesar 667 unit. Sedangkan biaya produksi perabotan dan pengolahan kayu UD. Dirgantara adalah Rp 159.531.733 pertahun, dengan volume produksi mencapai 659 unit.

2. Usaha pengolahan kayu dan perabot UD. Auzar Bersaudara dan UD Dirgantara dinyatakan layak dengan nilai BCR sebesar 1,48 dan 1,36. 
Saran

Saran yang dapat disampaikan yaitu:

1. Sebaiknya pemilik usaha membuat pembukuan yang lebih jelas untuk mengetahui rincian biaya yang lebih akurat.

2. Dalam menentukan harga jual sebaiknya perusahaan memper-hitungkan biaya penyusutan mesin, peralatan dan kendaraan. Selain itu juga biaya perawatan mesin, peralatan dan kendaraan juga diperhitungkan dalam menentukan harga jual.

\section{DAFTAR PUSTAKA}

Anita, U. 2013. Analisis Perhitungan Harga Pokok Produksi Sebagai Dasar Penetapan Harga Jual Produk Furniture (Studi kasus pada PT. Hanin Designs Indonesia Indonesian Legal Wood). Fakultas Ekonomi dan Bisnis Jurusan Akuntansi S1.Universitas Dian Nuswantoro Semarang. Semarang.

Asyisifa.2009. Analisis Biaya Dan Pendapatan Industri Mebel Jati Di Banjarbaru Kalimantan
Selatan.Program Studi

Manajemen Hutan, Fakultas Kehutanan. Universitas Lambung Mangkurat. Pontianak.

Hermanto.2009. Analisis Biaya Produksi Dan Pemasaran Pada Industry Kecil Kusen (Studi Kasus Di Industri Kecil Kusen Surya Perabot Desa Titian Resak Kecamatan

Seberida.[Skripsi]. Fakultas Kehutanan. Universitas Lancang Kuning. Pekanbaru.

Iryadini, L. 2010. Analisis Faktor Produksi Industri Kecil Kerupuk Kabupaten Kendal. [Skripsi]. Fakultas Ekonomi. Universitas Diponegoro. Semarang.

Kesuma, et al,. 2014. Analisa Kelayakan Finansial Pengembangan Usaha Produksi Komoditas Lokal: Mie Berbasis Jagung. [Jurnal].Agritech Vol. 34, No. 2, Mei 2014.Balai Besar Pengembangan Teknologi Tepat Guna. Lembaga IImu Pengetahuan Indonesia.Subang. Jawa Barat.

Mulyadi. 2010. Akuntansi Biaya. UPP-STIM-YKPN, Yogyakarta.

Nurcahyo, DF. 2011. Analisis Kelayakan Bisnis (Studi kasus di PT. Pemuda Mandiri Sejahtera). Fakultas Teknik. Program 
Studi Teknik Industri.

Depok.

Putri, Y.E. 2016.Analisis

Kelayakan Finansial Usaha

Produksi Mebel (Studi

Kasus Di Industri Kecil

Hero Perabot Kelurahan

Maharatu Kecamatan

Marpoyan Damai,

Pekanbaru). [Skripsi].

Fakultas Kehutanan.

Universitas Lancang

Kuning. Pekanbaru.

Wijaya, Yuke O. 2012. Analisis

Pengendalian Biaya

Produksi dan Pengaruhnya

Terhadap Laba Pabrik

Penggilingan (PP) Srikandi

Palembang. Akuntansi.

STIE MDP. Pelembang. 